\title{
PENGEMBANGAN MODUL PRAKTIKUM KIMIA BAHAN ALAM: ISOLASI SENYAWA STIGMASTERROL DARI DAUN TUMBUHAN MAJAPAHIT (Crescentia cujete)
}

\author{
Shalat Muliani $^{{ }^{*}}$, Aliefman Hakim ${ }^{2}$, Syarifa Wahidah Al Idrus ${ }^{3}$ \\ ${ }^{12}$ Program Studi Pendidikan Kimia, Universitas Mataram. Jalan Majapahit No. 62 Mataram, NTB \\ 83112, Indonesia. \\ *Coresponding Author. E-mail: shalatmuliani98@gmail.com
}

\author{
Received: 21 Oktober 2020 Accepted: 13 Agustus 2021 Published: 30 November 2021 \\ doi: 10.29303/cep.v4i3.2129
}

\begin{abstract}
Abstrak
Penelitian ini bertujuan untuk mengembangkan modul praktikum kimia bahan alam isolasi senyawa stigmasterol dari daun tumbuhan majapahit (Crescentiacujete). Penelitian ini termasuk ke dalam jenis penelitian dan pengembangan ( $R \& D$ ) dengan model 4D (define, desaign, develop dan disseminate). Proses isolasi senyawa menggunakan metode modifikasi yang diawali dengan tahap maserasi, penguapan, rekristalisasi dan identifikasi struktur dengan menggunakan spektroskopi IR dan UV-Vis. Hasil penelitian diperoleh kristal/serbuk berwarna putih sebanyak $400 \mathrm{mg}$. Hasil pengukuran spektrum IR menunjukkan pita serapan pada bilangan gelombang $3456,72 \mathrm{~cm}^{-1}, 2918,32 \mathrm{~cm}^{-1}$, $2849,74 \mathrm{~cm}^{-1}, 1638,57 \mathrm{~cm}^{-1}, 1473,5 \mathrm{~cm}^{-1}, 1463,36 \mathrm{~cm}^{-1}, 1288,43 \mathrm{~cm}^{-1}, 729,94 \mathrm{~cm}^{-1}, 719,6 \mathrm{~cm}^{-1}$. Hasil pengukuran spektrum UV-Vis menunjukkan serapan maksimum pada bilangan gelombang 243 nm.Berdasarkan hasil analisis spektroskopi, senyawa hasil isolasi merupakan stigmasterol dengan rumus molekul $\mathrm{C}_{29} \mathrm{H}_{48} \mathrm{O}$. Modul yang dikembangkan dianalisis kevalidannya dengan rumus indeks Aiken dan didapatkan nilai V 0,79 dengan kategori valid dan hasil dilakukan analisis reliabilitas dengan nilai 0,89 sehingga modul layak digunakan. Analisis kepraktisan modul untuk semua aspek didapatkan rata-rata kepraktisan angket respon mahasiswa 82\% dengan kategori sangat praktis.
\end{abstract}

Kata Kunci: isolasi, pengembangan modul, stigmasterol.

\section{Development of Chemical Practicum Module of Natural Materials: Isolation of Stigmasterrol Compounds From the Leaves of Majapahi Plant (Crescentia cujete)}

\begin{abstract}
This study aims to develop a chemical laboratory module for the isolation of stigmasterol compounds from the leaves of the majapahit plant (Crescentia cujete). This research is included in the type of research and development $(R \& D)$ with the $4 D$ model (define, design, develop and disseminate). The process of compound isolation uses a modified method that begins with maceration, evaporation, recrystallization and identification of the structure using IR and UV-Vis spectroscopy. The results showed that $400 \mathrm{mg}$ of white crystals / powder. The IR spectrum measurement results show the absorption band at wave numbers $3456.72 \mathrm{~cm}-1,2918.32 \mathrm{~cm}-1,2849.74 \mathrm{~cm}-1,1638.57 \mathrm{~cm}-1,1473.5$ $\mathrm{cm}-1,1463.36 \mathrm{~cm}-1,1288.43 \mathrm{~cm}-1,729.94 \mathrm{~cm}-1,719.6 \mathrm{~cm}-1$. The UV-Vis spectrum measurement results showed the maximum absorption at a wave number of $243 \mathrm{~nm}$. Based on the results of spectroscopic analysis, the isolated compound was stigmasterol with the molecular formula $\mathrm{C}_{29} \mathrm{H}_{48} \mathrm{O}$. The module developed for its validity analysis with the Aiken formula and obtained a V value of 0.79 in the valid category and the results of the reliability analysis with a value of 0.89 so that the module is feasible to use. Analysis of the practicality of the module for all aspects obtained an average of $82 \%$ practicality for student response questionnaires with the very practical category.
\end{abstract}

Keywords: isolation, module development, stigmasterol. 


\section{Chemistry Education Practice, 4 (3), 2021 - 225}

Muliani, Hakim, Idrus

\section{PENDAHULUAN}

Indonesia merupakan salah satu pusat keanekaragaman hayati terkaya di dunia dan dikenal sebagai negara mega-biodiversity. Keanekaragaman ini disebabkan oleh letak Indonesia yang strategis di antara dua benua yaitu benua Asia dan benua Australia, sehingga berbagai jenis tumbuhan yang ada di Indonesia merupakan perpaduan dari dua benua tersebut (Ilyas, 2015). Keanekaragaman hayati tersebut banyak dimanfaatkan sebagai sumber untuk memperoleh senyawa metabolit sekunder yang meliputi golongan alkaloid, flavonoid, steroid dan terpenoid (Mainawati, 2017).

Senyawa metabolit sekunder yang terdapat dalam tumbuhan merupakan zat bioaktif yang berkaitan dengan kandungan kimia dalam tumbuhan dan dapat pula diartikan sebagai mekanisme pertahanan diri terhadap acaman lingkungan, sehingga tumbuhan dapat digunakan sebagai bahan obat untuk berbagai macam penyakit (Yuda dkk, 2017). Metabolit sekunder dalam tumbuhan tersebar merata ke seluruh bagian tumbuhan namun dalam kadar yang berbeda (Firjatillah dkk, 2020).

Salah satu tumbuhan yang sering ditemukan di sekitar masyarakat yaitu tumbuhan majapahit (crescentia cujete). Tanaman ini merupakan jenis tanaman dikotil berbunga yang berasal dari Grenada (Fardilla dkk, 2018). Majapahit merupakan tumbuhan yang masuk ke dalam genus Crecentia dan family bignoniaceae dan dikenal dengan nama buah bile di daerah Lombok. Menurut Widyaningrum (2011) secara tradisional maja dijadikan sebagai obat untuk luka gatal, demam, diare, dan hipokondria, dan penurun tekanan darah tinggi atau hipertensi dengan meminum air rebusannya.Buah maja mengandung fenolik, flavonoid, tannin, sapoin, alkaloid, dan cardenolid. Ekstrak methanol daun majapahit mengandung triterpenoid, alkaloid, fenolik, dan saponin.

Senyawa utama dari ekstrak daun majapahit diidentifikai sebagai tannin, skimmianin, essensial oil (sebagian besar caryophillena, cineole, citral, citronellal, Dlimonena, dan eugenol) sterol, triterpenoid, flavonoid, dan kumarin. Ekstrak daun tumbuhan majapahit menghasilkan essensial oil yang mempunyai aktivitas antifungal juga terbukti berpengaruh mengurangi aktivitas bakteri Aeromonas hydrophila pada budidaya ikan Nila (Oreochromis niloticus) (Luthfi dkk, 2017).
Menurut Nurhasanah (2014), ekstrak nheksana daun tumbuhan majapahit mengandung senyawa alkaloid, steroid, polifenol dan saponin. Kemudian penelitian yang dilakukan oleh Intan Fardilla dan Nurul Hidajati (2018) berhasil mengidentifikasi senyawa stigmasta-5,22-dien3 - $\beta$-ol atau stigmasterol yang terkandung dalam ekstrak n-heksana daun tumbuhan majapahit. Stigmasterol merupakan turunan dari golongan steroid. Steroid merupakan kelompok senyawa dengan struktur dasar 17 atom karbon dan 4 cincin, dengan 3 cincin sikloheksana dan satu cincin siklopentana.

Pada umumnya steroid berfungsi sebagai hormon, sumber aprodisiaka alami, dan penambah vitalitas (Meydia, 2016). Steroid juga berfungsi menjaga keseimbangan garam, mengendalikan metabolisme dan meningkatkan fungsi organ seksual (Nasrudin, 2017). Beberapa senyawa steroid mempunyai aktivitas antiinflamasi atau anti peradangan (Salempa, 2014). Sterol tumbuhan yang telah lama dikenal adalah campesterol, stigmasterol, dan $\beta$ sitosterol.Stigmasterol berfungsi mencegah penyakit kanker tertentu, seperti kanker ovarium, prostat, payudara dan kanker usus besar karena mempunyai potensi antioksidan, hipoglikemik dan mampu menghambat tiroid (Gabay dkk, 2010).

Salah satu cabang ilmu kimia yang concern terhadap pemanfaatan tumbuhan obat adalah Kimia Bahan Alam. Mata kuliah kimia bahan alam merupakan mata kuliah yang wajib diprogramkan untuk mahasiswa program studi S1 Pendidikan Kimia, Fakultas Keguruan dan Ilmu Pendidikan, Universitas Mataram dengan bobot 2 sks teori dan 1 sks praktikum. Kegiatan praktikum pada pembelajaran kimia bahan alam biasanya berbasis proyek yaitu mengisolasi senyawa metabolit sekunder dari tumbuhan. Kurangnya pengetahuan dan minimnya sumber belajar membuat mahasiswa kesulitan. Oleh karena itu peranan sumber belajar sangat diperlukan dalam proses pembelajaran guna pencapaian pemahaman yang utuh, sehingga pengembangan modul praktikum perlu dilakukan.

Modul praktikum yang dibuat secara sistematis berisi tentang langkah-langkah untuk melakukan isolasi senyawa stigmasterol dari daun tumbuhan majapahit. Modul dirancang untuk membantu peserta didik menguasai tujuan belajar dan sebagai sarana siswa secara mandiri sesuai kecepatan masing-masing (Istanti, 2015). Melalui penggunaan modul, peserta didik 
memiliki efektivitas waktu belajar karena tidak harus menuggu temannya yang kecepatannya beragam (Sari dkk, 2020). Penggunaan modul dalam proses pembelajaran juga telah terbukti mampu meningkatkan kualitas pembelajaran (Sasmita dan Fajriyah, 2018).

Berdasarkan manfaat yang dimiliki stigmasterol, maka dilakukanlah pengembangan modul praktikum kimia bahan alam: isolasi senyawa stigmasterol dari daun tumbuhan majapahit (Crescentiacujete). Pada proses pengembangan modul praktikum bagaimanakah langkah-langkah pengembangan modul, apakah modul yang dikembangkan layak dan praktis?. Berdasarkan latar belakang di atas, maka penelitian ini dilakukan dengan tujuan mengisolasi senyawa metabolit sekunder stigmasterol dari ekstrak n-heksana daun tumbuhan majapahit (Crescentia cujete), serta mengembangkan modul praktikum kimia bahan alam yang layak dan praktis.

\section{METODE}

Penelitian ini dilaksanakan selama 8 bulan dimulai dari bulan Juni 2019 sampai Februari 2020 di Laboratorium Kimia, Fakultas Keguruan dan Ilmu Pendidikan, Universitas Mataram.

\section{Isolasi Stigmasterol}

Alat dan Bahan

Alat-alat yang digunakan pada penelitian ini adalah botol kaca, gunting, hot plate, gelas kimia, pipet tetes, corong Buchner, corong kaca, timbangan, neraca analitik, gelas ukur, botol semprot, pipa kapiler, oven, batang pengaduk, thermometer, klem, statif, botol vial, plat KLT, lampu UV, spektroskopi UV-Vis dan spektroskopi FT-IR.

Bahan-bahan yang digunakan pada penelitian ini adalah sampel daun tumbuhan majapahit (Crescentia cujete), n-heksana teknis, methanol teknis, etyl asetat teknis, aquades, $\mathrm{H}_{2} \mathrm{SO}_{4} 2 \mathrm{M}$, plastic bening dan kertas saring.

\section{Prosedur kerja dengan metode modifikasi}

Daun majapahhit (Crescentia cujetea) segar dibersihkan dengan air mengalir dan dikeringkan dengan tidak disiniari langsng sinar matahari. Daun yang telah kering kemudian dipotong kecil-kecil dan dimaserasi dengan nheksana selama 5 hari sambil sesekali diaduk.Sampel dipanaskan hingga mendidih, kemudian disaring dalam keadaan panas. Ekstrak keyang diperoleh dipekatkan hingga tersisa seperempat dari volume awal, kemudian diuapkan pada suhu ruangan hingga kering.

Ke dalam ekstrak kering dimasukkan $400 \mathrm{~mL}$ larutan campuran etil asetat dan methanol dengan perbandingan (1:1). Sampel dipanaskan kembali pada suhu $60{ }^{\circ} \mathrm{C}$ hingga tersisa seperempat dari volume awal. Larutan didiamkan hingga terbentuk endapan. Endapan yang dihasilkan dipisahkan dari pengotor dan pelarutnya dengan cara dekantasi. Endapan ditambahkan dengan pelarut untuk rekristalisasi yaitu methanol dan etil asetat dengan perbandingan 2:1. Proses rekristalisasi dilakukan berulang hingga warna larutan menjadi bening dan diperoleh kristal/serbuk putih. Isolat yang diperoleh dikarakterisasi dengan spektrofotometer UV-Vis dan spektrofotometer FT-IR untuk mengetahui bilangan gelombang yang dapat menunjukkan gugus fungsi yang dimiliki isolat.

\section{Pengembangan modul}

Penelitian ini termasuk jenis penelitian dan pengembangan (research and development). Adapun yang dikembangkan dalam penelitian ini adalah modul praktikum kimia bahan alam, isolasi senyawa stigmasterol dari daun tumbuhan majapahit. Penelitian ini menggunakan rancangan penelitian model $4 \mathrm{D}$ yang terdiri dari tahap pendefinisian (define), perancangan (design), pengembangan (development) dan penyebaran (disseminate). Pada tahap define dilakukan analisis awal akhir dan analisis materi. Analisis awal akhir dilakukan dengan menganalisis rancangan pembelajaran semester (RPS), rancangan tugas mahasiswa (RTM), sehingga peneliti menetapkan bahwa modul yang dikembangkan akan digunakan dalam pembelajaran selama satu semester. Analisis jurnal.juga dilakukan untuk membuat skema kerja modifikasi yang akan digunakan pada modul praktikum. Kegiatan pada tahap ini adalah melakukan telaah terhadap kimia bahan alam yaitu isolasi senyawa stigmasterol dari daun tumbuhan majapahit baik secara teoritis maupun prosedural.

Pada tahap design dilakukan pembuatan rancangan awal komponen modul praktikum, yang dibagi menjadi dua tahap yaitu menentukan format modul praktikum dan menyusun rancangan awal produk. Sehingga dihasilkan modul praktikum protpotype 1.Tahapan selanjutnya yaitu development. Pada tahap ini prototype 1 yang telah dibuat akandiuji validitasnya oleh para ahli dan akan dilakukan uji coba terbatas pada sampel yang telah 
ditentukan. Analisa data untuk uji validitas ahli menggunakan indeks Aiken (V) (Retnawati, 2016).

$$
\mathrm{V}=\frac{\sum s}{n(c-1)}
$$

Dengan $\mathrm{V}=$ indeks kesepakatan rater mengenai validitas butir.

$\mathrm{S}=$ skor yang ditetapkan setiap rater dikurangi skor terendah dalam kategori yang dipakai $(\mathrm{s}=\mathrm{r}-\mathrm{I}$, dengan $r=$ skor kategori pilihan rater dan $I_{0}=$ skor terendah penskoran)

$\mathrm{n}=$ banyaknya rater

$\mathrm{c}=$ banyaknya kategori yang dipilih rater

Analisis yang digunakan untuk mengetahui tingkat reliabilitas oleh dua orang pengamat validator (pada dua aspek yang sama) pada lembar instrument modul, digunakan rumus Percentage of Agreement sebagai berikut: (Borich dalam Mustaming dkk, 2015).

$$
(R)=\left[1-\frac{A-B}{A+B}\right] \times 100 \%
$$

Keterangan:

$\mathrm{A}=$ hasil penelitian pengamat yang memberikan nilai lebih tinggi.

$\mathrm{B}=$ hasil penilaian pengamat yang memberikan nilai lebih rendah.

Instrument dikatakan baik jika mempunyai indeks kesepahaman $\geq 0,75$ atau $\geq$ 75\% (Borich dalam Mustaming dkk, 2015).

Analisis data angket praktikalitas menggunakan rumus:

$$
\mathrm{p}=\frac{f}{N} \times 100 \%
$$

Keterangan:

$$
\begin{aligned}
& \mathrm{p}=\text { nilai akhir } \\
& \mathrm{f}=\text { perolehan skor } \\
& \mathrm{N}=\text { skor maksimum }
\end{aligned}
$$

Tahapa terakhir pada model 4D yaitu penyebaran modul.

\section{HASIL DAN PEMBAHASAN}

\section{Uji Kemurnian Senyawa Hasil Isolasi}

Proses pemurnian isolat dilakukan dengan metode reksristalisasi. Endapan yang terbentuk direkristalisasi dengan menggunakan pelarut etil asetat teknis dan methanol teknis dengan perbandingan larutan 1:2 secara berulang hingga dihasilkan endapan berwarna putih dengan larutan berwarna bening. Rekristalisasi dilakukan untuk memurnikan senyawa kimia dari pengotornya. Setelah direkristalisasi beberapa kali akhirnya didapatkan serbuk putih stigmasterol dengan massa $400 \mathrm{mg}$.

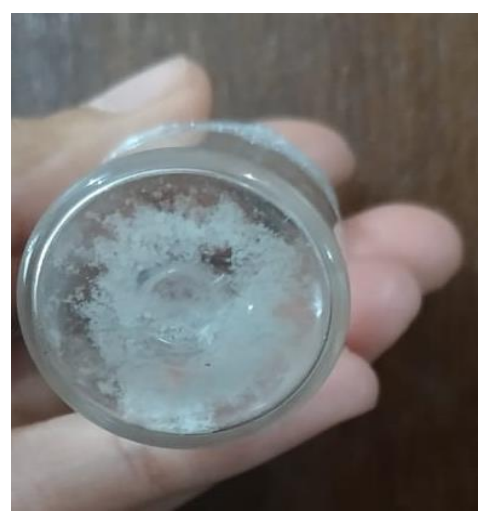

Gambar 1. Serbuk stigmasterol hasil isolasi

Terhadap isolat yang dihasilkan, dilakukan uji kemurnian dengan menggunakan kromatografi lapis tipis. Analisis KLT menggunakan eluen n-heksana dan etil asetat dengan perbandingan 5:5. Deteksi dengan menggunakan lampu UV $254 \mathrm{~nm}$ tidak menunjukkan adanya noda yang berpendar, menunjukkan bahwa struktur kimia isolat tidak memiliki ikatan rangkap terkonjugasi. Noda hasil elusi yang tidak tampak dibawah lampu UV disemprot dengan larutan $\mathrm{H}_{2} \mathrm{SO}_{4} \quad 5 \quad \mathrm{M}$ kemudian dioven selama 5-10 menit sehingga diperoleh noda berwarna ungu dan dapat disimpulkan bahwa isolat relative murni secara KLT.

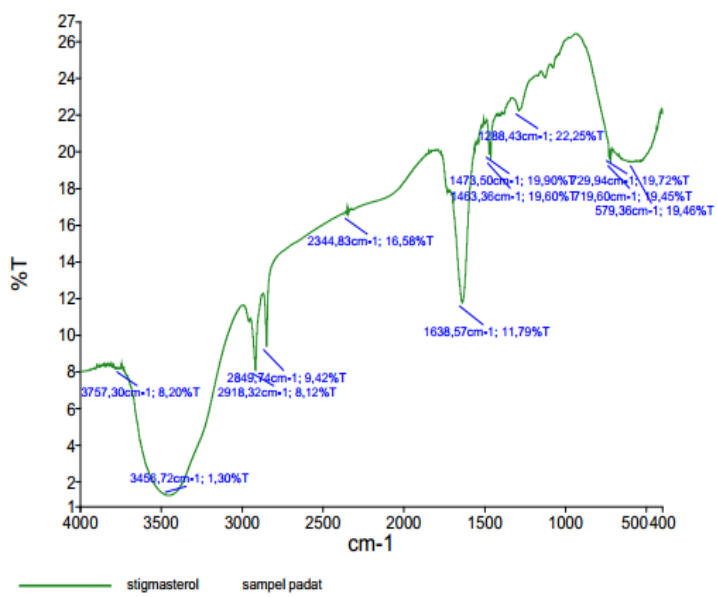

Gambar 2. Spektrum IR stigmasterol hasil isolasi

Identifikasi isolat dilakukan dengan analisis spektroskopi infra merah (IR) dengan pellet $\mathrm{KBr}$ dan spektroskopi UV-Vis. Hal ini dilakukan untuk memastikan isolat yang didapatkan adalah senyawa stigmasterol.Analisis spektrum IR isolat memberikan serapan pada 
daerah bilangan gelombang $3456,72 \mathrm{~cm}^{-1}$ yang diduga merupakan serapan ulur dari gugus $\mathrm{O}-\mathrm{H}$ (3230-3550 $\left.\mathrm{cm}^{-1}\right)$. Pita serapan C-O pada panjang gelombang $1288,43 \mathrm{~cm}^{-1}$. Pita serapan pada bilangan gelombang 1638,57 $\mathrm{cm}^{-1}$ menunjukkan adanya uluran $\mathrm{C}=\mathrm{C}$ nonkonjugasi.

Analisis selanjutnya menggunakan spektroskopi UV-Vis dengan tujuan mengetahui panjang gelombang maksimum senyawa. Data spektrum UV-Vis hasil senyawa terdapat puncak dengan serapan maksimum pada daerah panjang gelombang $243 \mathrm{~nm}$ yang dapat dilihat pada Gambar 3. Data spektrum menunjukkan tidak adanya ikatan rangkang terkonjugasi dalam senyawa hasil isolasi. Ikatan rangkap terkonjugasi biasanya ditandai dengan serapan maksimum yang terjadi pada bilangan gelombang $\geq 250 \mathrm{~nm}$.

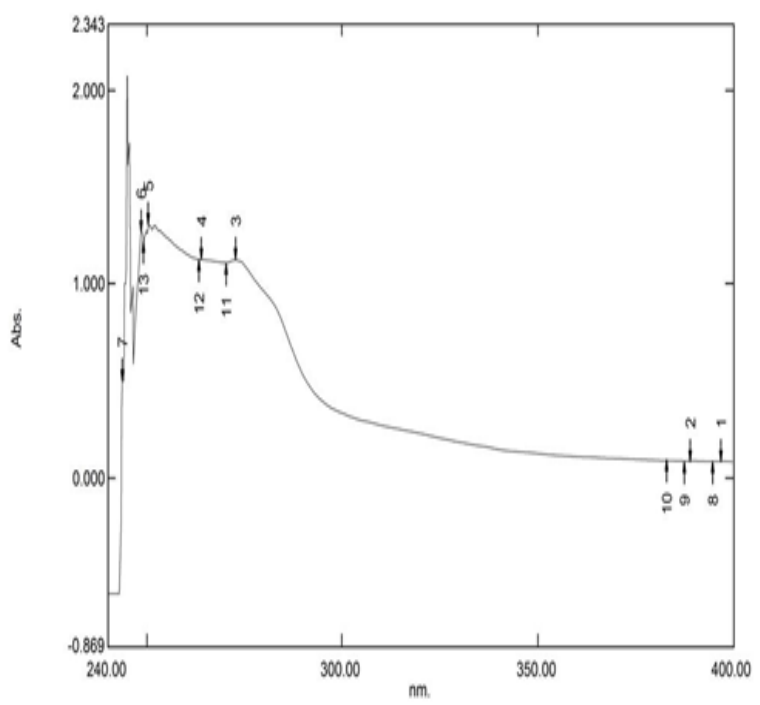

Gambar 3. Spektrum UV-Vis stigmasterol hasil isolasi

\section{Hasil Penelitian Modul Praktikum}

Tabel 1. Hasil Validasi Modul

\begin{tabular}{lll}
\hline No & Butir & V \\
\hline 1 & Komponen kegrafikan & 0,82 \\
2 & Komponen penyajian & 0,72 \\
3 & Komponen kelayakan isi & 0,80 \\
4 & Komponen penyajian & 0,83 \\
\hline
\end{tabular}

Hasil analisis lembar validasi modul praktikum kimia bahan alam tentang isolasi senyawa stigmasterol dari daun tumbuhan majapahit (Crescentia cujete) yang dinilai oleh dua orang validator dan diperoleh nilai $\mathrm{V}$ ratarata yaitu 0,79 dengan kategori valid.
Tabel 2. Hasil Uji Reliabilitas

\begin{tabular}{cllll}
\hline No & $\begin{array}{l}\text { Komponen } \\
\text { perilaku pada } \\
\text { modul }\end{array}$ & \multicolumn{3}{l}{$\begin{array}{l}\text { Rata-rata komponen } \\
\text { modul }\end{array}$} \\
\cline { 3 - 5 } & $\mathbf{A}$ & $\mathbf{B}$ & $\mathbf{R}$ \\
\hline 1 & $\begin{array}{l}\text { Komponen } \\
\text { kegrafikan }\end{array}$ & 3,85 & 3,02 & 0,87 \\
2 & $\begin{array}{l}\text { Komponen } \\
\text { penyajian }\end{array}$ & 3,2 & 3 & 0,96 \\
3 & $\begin{array}{l}\text { Komponen } \\
\text { kelayakan isi } \\
\text { Komponen } \\
\text { kebahasaan }\end{array}$ & 3,5 & 3,25 & 0,96 \\
\hline
\end{tabular}

Hasil uji reliabilitas modul rata-rata yaitu 0,91. Dengan nilai komponen kegrafikan, komponen penyajian, komponen kelayakan isi, dan komponen kebahasaan dengan nilai berturuturut yaitu 0,$87 ; 0,96 ; 0,96$ dan 0,86 . Sehingga dapat disimpulkan bahwa modul praktikum kimia bahan alam tentang isolasi senyawa stigmasterol dari daun tumbuhan majapahit telah reliabel atau dapat dipercaya dengan nilai $\mathrm{R}>0,75$. Berikut adalah grafik aspek kepraktisanmodul yang dapat dilihat pada gambar 4.

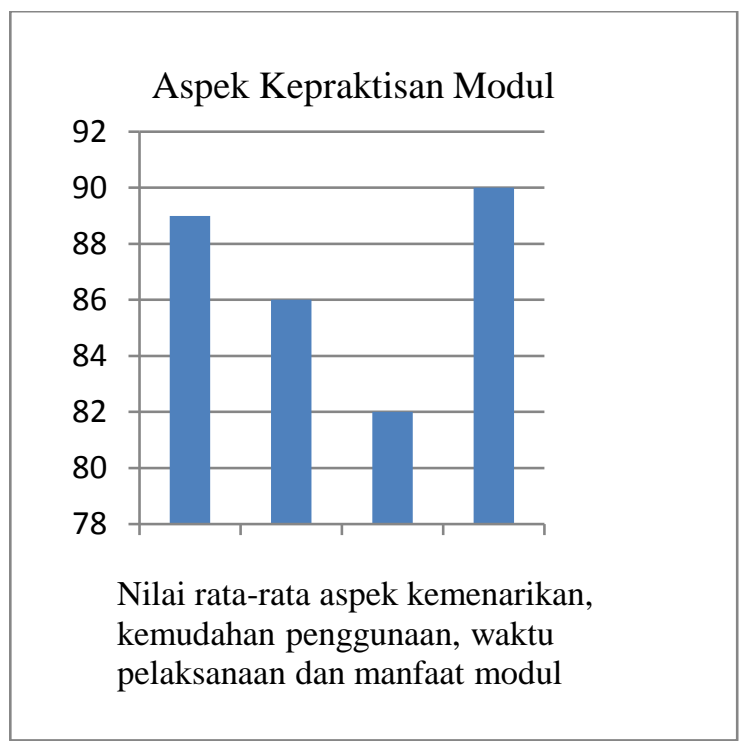

Gambar 4. Aspek kepraktisan modul praktikum

Analisis respon mahasiswa menggunakan angket respon untuk mengukur kepraktisan modul untuk keseluruhan aspek yang terdiri dari dari aspek kemenarikan, kemudahan penggunaan, waktu pelaksanaan dan manfaat modul, diperoleh rata-rata mahasiswa merespon baik terhadap modul praktikum isolasi senyawa stigmasterol dari daun tumbuhan majapahit (Crescentia cujete) yang dikembangkan dengan rata-rata kepraktisan 
angket respon mahasiswa $82 \%$ dengan kategori sangat praktis

\section{SIMPULAN}

Berdasarkan hasil analisis spektroskopi senyawa metabolit sekunder yang dilakukan dengan metode modifikasi, berhasil diisolasi dari ekstrak n-heksan daun majapahit crescentiacujete senyawa stigmasterol dengan rumus molekul $\mathrm{C}_{29} \mathrm{H}_{48} \mathrm{O}$.Pengembangan modul praktikum kimia bahan alam isolasi stigmasterol dari daun tumbuhan majapahit menggunakan metode pengembangan dan penelitian (R\&D). Rancangan motode penelitian menggunakan model 4D yang terdiri dari empat tahapan yaitu define, desaign, develop, dan disseminate. Hasil analisis lembar validasi modul praktikum kimia bahan alam tentang isolasi senyawa stigmasterol dari daun tumbuhan majapahit (Crescentia cujete) yang dinilai oleh dua orang validator dan diperoleh nilai $\mathrm{V}$ yaitu 0,79 dengan kategori valid dan nilai reliabilitas 0,91 sehingga modul layak digunakan untuk kegiatan pembelajaran. Begitu juga dengan hasil analisis respon mahasiswa menggunakan angket respon untuk mengukur kepraktisan modul untuk keseluruhan aspek diperoleh rata-rata mahasiswa merespon baik terhadap modul praktikum isolasi senyawa stigmasterol dari daun tumbuhan majapahit (Crescentia cujete) yang dikembangkan dengan rata-rata kepraktisan angket respon mahasiswa $82 \%$ dengan kategori sangat praktis

\section{DAFTAR PUSTAKA}

Fardilla, Intan \& Nurul Hidajati. (2018). Isolasi Senyawa Metabolit Sekunder Dari Ekstrak N-Heksana Daun Tumbuhan Majapahit (Cerscentia Cujete). Journal Of Chemistry 7(1).

Firjatillah, M., Junaidi, E., \& Hakim, A. (2020). Pengembangan Petunjuk Praktikum Kimia Bahan Alam: Ekstraksi Senyawa Kardol dari Kulit Biji Jambu Mete. Chemistry Education Practice, 3(2), 116-122.

Gabay, O., Sanchez., Salvat. (2010). Stigmasterol; A Phytosterol With Potential Anti Osteoarthritic Properties. Am J Clin Nutr 18, 106-116.

Ilyas, Asriani., Iin Novianty, \& Irmayanti. (2015). Senyawa Golongan Steroid Dari Ekstrak N-Heksana Kulit Batang Kayu Biti (Vitex cofassus) Dan Uji Toksisitas Terhadap Artemia salina Leach.
Chemical At Natura Acta Vol 3(3), 119123.

Istanti, V. (2015). Pengembangan Modul Ilmu Pengetahuan Alam Bagi Siswa Kelas IV Sekolah Dasar. E-Journal Skripsi.

Luthfi, Miftahul., Sri R., \& Achmad S. (2017). Pengaruh Ekstrak Daun Majapahit (Crescentia Cujete) dengan Dosis Yang Berbeda Untuk Mengurangi Aktivitas Bakteri Aeromonas hydrophila Pada Budidaya Ikan Nila (Orechromis Niloticus).Prosiding Seminar Nasional Hasil Penelitian Dan Pengabdian Kepada Masyarakat Vol 2, 209-214.

Mainawati, D. (2017). Uji Kandungan Metabolit

Sekunder Tumbuhan Obat Yang terdapat Di Kecamatan Rambah Samo Kabupaten Rokan Hulu (Doctoral dissertation, Universitas Pasir Pengaraian).

Meydia., Ruddy Suwandi \& Pipih Suptijah. (2016). Isolasi Senyawa Steroid Dari Teripang GAMA (Stichopus variegatus) Dengan Berbagai Jenis Pelarut. JPHPI Vol. 19 No. 3.

Mustaming, A. Cholik, M. \& Nurlaela, L. (2015). Pengembangan Perangkat Pembelajaran Memperbaiki Unit Kopling dan Komponen-Komponen Sistem Pengoperasiannya dengan Model Discovery Learning untuk Meningkatkan Hasil Belajar Siswa Kelas XI Otomotif SMK Negeri 2 Tarakan.Jurnal Pendidikan Vokasi: Teori dan Praktek, Vol. 3, No. 1 hal: 8195.

Nasrudin, Wahyono, Mustofa, \& Ratna Susidarti. (2017). "Isolasi Senyawa Steroid Dari Kulit Akar Senggugu (Cleodendrum serratum L. Moon)". Jurnal Ilmiah Farmasi 6(3).

Nurhasanah, H. Uji Bioaktivitas Ekstrak Daun Maja (Crescentia cujete Linn) Sebagai Anti Rayap. Jurnal Kimia Khatulistiwa, 3(3).

Salempa, Pince. (2014). Isolasi dan Identifikasi Senyawa Metabolit Sekunder Ekstrak N-Heksana Daun Tumbuhan Maja (Aegle Marmelos Linn.) Jurnal Sainsmat Vol. 3(2), 185-190.

Sari, A., Savalas, L. R. T., \& Hakim, A. (2020). Pengembangan Modul Praktikum Kimia Bahan Alam Tentang Isolasi Senyawa Dari Minyak Kayu Manis. Chemistry Education Practice, 3(1), 12-16. 


\section{Chemistry Education Practice, 4 (3), 2021 - 230}

Muliani, Hakim, Idrus

Sasmita, A., \& Fajriyah, K. (2018).

Pengembangan Modul Berbasis

Quantum Learning Tema Ekosistem

Untuk Kelas V Sekolah Dasar. Jurnal

Refleksi Edukatika Vol. 8 (2), 163-170.

Widyaningrum, Herlina. (2011). Kitab Tanaman

Obat Nusantara. Yogyakarta: Media

Pressindo. 